\title{
MEASUREMENTS OF SURFACE FREE ENERGY AS A TOOL TO ASSES THE EFFECT OF VARNISHING AND PRINTING OF THE PAPER SUBSTRATES
}

\author{
Zuzanna Żołek-Tryznowska (D), Marta Więcek \\ Warsaw University of Technology, Mechanics and Printing Institute, Faculty of Production \\ Engineering, Warsaw, Poland
}

\begin{abstract}
Nowadays, printing products might be finished in various ways. Varnishing process is one of the most popular finishing method which gives various effect, such as mate, glossy etc. However, the varnish layer applied on the paper is very thin, therefore it can be invisible to the naked human eye. The aim of this work was to use contact angle measurement and surface free energy determination as a tool to assess the effect of printing and varnishing process of paper materials. We have used various tools in order to analyses the changes of surface: surface roughness, gloss, water contact angle absorption and surface free energy determination. Those tools were used in order to confirm whether the print has been covered with varnish or not.

In this work six various paper substrates were used (glossy, coated and un-coated papers). The printing and varnishing was performed in laboratory conditions using flexographic water-based printing and waterbased varnish. Samples were prepared as follows: paper with ink coating, paper with varnish coating and paper with ink layer and varnish layer on the top. The surface roughness was determinated of all samples and compared. The surface roughness changes were observed for pure paper, overprinted and overvarnished. Next, the gloss of samples prior and after printing and varnishing was measured. The gloss of the samples increases when they are printed or varnished, what is related with properties of ink and varnish. Also, the thickness of ink and varnish layers was determinated. The thickness of the samples increases when the number of layers increases. Finally, the water contact angle was measured and surface free energy was calculated with Owens-Wendt method.

Our results reveal the possibility of using various tools in order to confirm the performance of varnishing of the prints. The printing with various colors is always seen by the naked human eye. On the other hand, the varnish layer might be not visible. However, such a comparison is not possible if we do not have the pure paper substrates prior printing or varnish.
\end{abstract}

Key words: contact angle, surface free energy, paper varnishing, paper finishing

\section{INTRODUCTION}

Paper is one of the most important carriers of the information (Car et al, 2018). Moreover, the history of human culture and civilization is directly connected with the history of paper. Nowadays, a large variety of paper are produced to suit to the customer requirements. Paper can be impregnated, coated, laminated, creped, molded etc. (Holik et al, 2013). One of the technique used to improve the paper and print resistance and its appearance is varnishing process (Majnarić et al, 2012). Various varnishes might be used, i.e. matt and gloss water based dispersive varnish, oil-base and UV varnish (Hudika et al, 2018). The typical varnish layers are applied with a thicknesses between about 0.5 and $6 \mu \mathrm{m}$ depending on the specific printing method and the chemistry of the printing inks and varnishes (Mirschel et al, 2013). This roughly corresponds to coating weights from 0.6 to $7 \mathrm{~g} \mathrm{~m}^{-2}$. Additionally, the composition of the varnish and the choice of a paper substrate used for printing may strongly influence the final coating properties.

The purpose of this analysis is estimation - which indirect methods might be used in order to evaluate whether the printing is enriched with transparent varnish layer or not. In the case of color layers of printing inks, the quality of the layer might be checked with reflectance densitometry or spectrophotometric techniques (Galić et al, 2015). However, this method are useless in the case of transparent layers. The goal was to assess the effect of varnished layer on the changes of the water contact values and surface free energy and its polar and dispersive components. Other methods, such as surface roughness, layer thickness and gloss measurement, were used in order to compare the influence of the printing and vanishing process on surface layer. The authors of this work, would like find answer, whether the measurements of the water contact angle are sufficient to evaluate the presence of varnish layer. 


\section{METHODS}

Six paper substrates were investigated: 1 - glossy, $73.5 \mu \mathrm{m}$ thickness; 2 - uncoated, $100 \mu \mathrm{m}$ thickness; 3 uncoated, $136 \mu \mathrm{m}$ thickness; 4 - uncoated, $70 \mu \mathrm{m}$ thickness; 5 - coated, $140 \mu \mathrm{m}$ thickness; 6 - coated, 143 $\mu \mathrm{m}$ thickness. The printing ink, color cyan and water-based dispersive varnish (SunChemicals) was used. Laboratory printing and varnishing was carried out with a K Paint Applicator coater (TMI Machines, UK) equipped with wire wound bar No. 1, which allows to obtain $6 \mu \mathrm{m}$ thickness of wet coating. Coating was performed under controlled environmental conditions $\left(23^{\circ} \mathrm{C}\right.$ and $50 \% \mathrm{RH}$ ).

The thickness was measured using digital thickness gauge FD-50 with the resolution $1 \mu \mathrm{m}$ with the error \pm 5 $\mu \mathrm{m}$. Data collection was performed at six different positions of the samples.

The surface roughness of the samples was measured by gauge SRT-220 roughness meter before and after printing or varnishing. It measures Ra and Rz parameters in a cut off path line of $0.8 \mathrm{~mm}$. In the present research, Ra parameter was only used to measure the roughness of the samples. The roughness value (Ra) was randomly measured 6 times on the surface of 2 various sample, the reported values are the average of these measurement.

The gloss (in the gloss units, GU) of the prints was measured at $20^{\circ}, 60^{\circ}$ and $85^{\circ}$ geometry conditions with the use of a Micro-Tri-Gloss glossmeter (BYK-Gardner, Germany). Data collection was performed at six different positions of the samples in both directions: cross and machine direction, and the reported values are the average of these measurements.

The contact angle of distilled water and diiodomethane (99\% Purity, CAS No. 75-11-6, Sigma-Aldrich) was measured using a DSA 100 drop shape analysis system (Krüss, Germany). The water contact angle was measured according to ISO 15989 standard. Smooth and horizontal sessile drops of the liquids (water, diiodomethane and printing ink) were deposited on a solid surface. Needles of $0.5 \mathrm{~mm}$ diameter were used for all liquids. The contact angle was measured on static drops. The drop shape analysis was done $15 \mathrm{~s}$ after the drop deposition with Tangent method 2. Environmental conditions were stable; with temperature 23 $\pm 1^{\circ} \mathrm{C}$. The reported contact angle values are the mean of five samples. The surface free energy of PE film was calculated with the Owens-Wendt method.

The results of measurements were presented as the mean \pm standard deviation. Statistical analysis was performed using one-way Analysis of Variance (ANOVA) employing the Statgraphics Centurion 18 (v.18.1.06 (StatPoint ${ }^{\circledR}$, Inc., USA) software. When ANOVA indicated a significant difference, the Tukey's honestly significant difference test (Tukey's HSD) was used to evaluate average differences (at a 95\% of confidence interval).

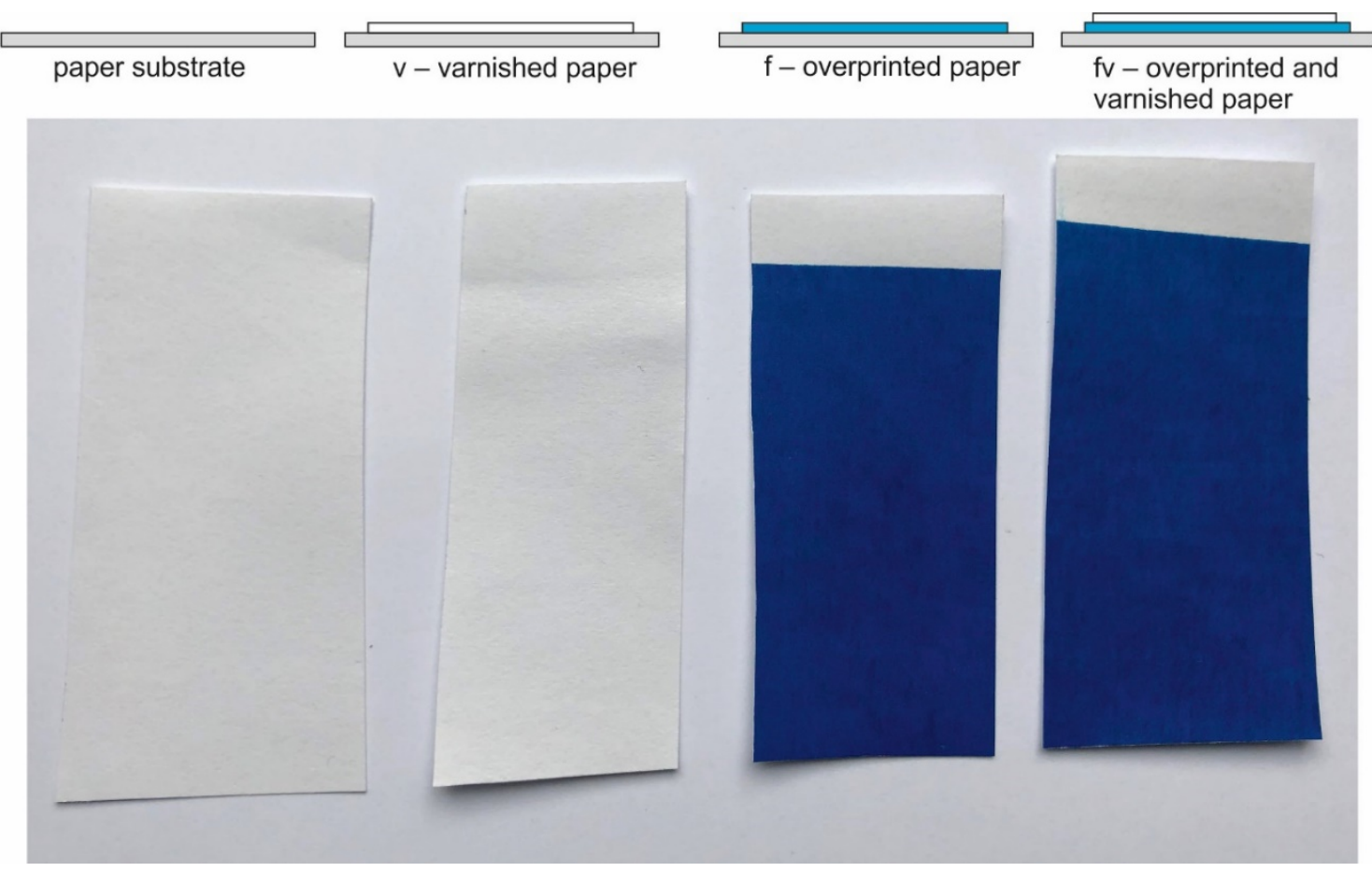

Figure 1: The samples of paper 3, overvarnished paper, over printed paper and both layer on th epaper 
Table 1: The values of thickness, values of gloss, water contact angle and surface free energy and its component of investigated samples: 1, 2, 3, 4, 5, 6-pure paper substrates; $v$-over varnished paper substrates; $f$-overprinted paper substrates; $f v$-overprinted with printing ink and afterwards finished with varnish

\begin{tabular}{|c|c|c|c|c|c|c|c|}
\hline Sample & $\begin{array}{c}\text { Thickness / } \\
\mu \mathrm{m}\end{array}$ & $\begin{array}{c}\text { Surface roughness / } \\
\mu \mathrm{m}\end{array}$ & Gloss / GU & Water CA / ${ }^{\circ}$ & $\begin{array}{c}\text { Polar } \\
\text { component / } \\
\mathrm{mJ} \cdot \mathrm{m}^{-2}\end{array}$ & $\begin{array}{c}\text { Dispersive } \\
\text { Component / } \\
\mathrm{mJ} \cdot \mathrm{m}^{-2}\end{array}$ & $\mathrm{SFE} / \mathrm{mJ} \cdot \mathrm{m}^{-2}$ \\
\hline 1 & $73.4 \pm 5.1^{a}$ & $1.204 \pm 0.400^{\mathrm{bc}}$ & $24.5 \pm 11^{\text {cde }}$ & $90.45 \pm 3.44^{\mathrm{hi}}$ & $1.83 \pm 0.91^{\mathrm{ab}}$ & $32.79 \pm 3.36^{\text {abcde }}$ & $34.62 \pm 2.98^{a b c}$ \\
\hline $1 \mathrm{v}$ & $83.3 \pm 1.7^{\mathrm{ab}}$ & $0.656 \pm 0.223^{\mathrm{ab}}$ & $35.95 \pm 2.9^{\text {def }}$ & $52.27 \pm 6.10^{b}$ & $18.89 \pm 3.54^{\mathrm{gh}}$ & $35.08 \pm 1.53^{\text {abcdef }}$ & $53.96 \pm 3.60^{\mathrm{ij}}$ \\
\hline 1f & $79.4 \pm 0.2^{b}$ & $0.845 \pm 0.289^{\mathrm{ab}}$ & $23.7 \pm 1.5^{\mathrm{cd}}$ & $86.11 \pm 4.97^{\mathrm{gh}}$ & $3.63 \pm 1.61^{\mathrm{abc}}$ & $30.10 \pm 3.32^{a}$ & $51.25 \pm 1.12^{\mathrm{ab}}$ \\
\hline $1 \mathrm{fv}$ & $95.1 \pm 2.8^{c}$ & $0.554 \pm 0.115^{a}$ & $39.0 \pm 1.6^{\mathrm{e}}$ & $55.92 \pm 1.58^{\mathrm{bcd}}$ & $17.08 \pm 1.22^{\mathrm{fgh}}$ & $34.17 \pm 1.32^{\text {abcde }}$ & $51.25 \pm 1.12^{\text {fghij }}$ \\
\hline 2 & $99.6 \pm 0.8^{\text {cd }}$ & $3.105 \pm 0.530^{g}$ & $5.5 \pm 1.7^{a}$ & $108.27 \pm 5.60^{\mathrm{j}}$ & $0.26 \pm 0.45^{a}$ & $31.38 \pm 2.04^{\mathrm{ab}}$ & $31.64 \pm 2.28^{a}$ \\
\hline $2 v$ & $101.7 \pm 0.6^{\text {cd }}$ & $2.047 \pm 0.289 \mathrm{def}$ & $7.0 \pm 0.5^{a}$ & $76.74 \pm 9.85^{\mathrm{fgh}}$ & $6.56 \pm 4.25^{\mathrm{abcd}}$ & $34.56 \pm 4.00^{\text {abcde }}$ & $41.12 \pm 3.68^{\text {bcde }}$ \\
\hline $2 f$ & $102.7 \pm 1.2^{\text {cd }}$ & $2.103 \pm 0.339$ def & $4.3 \pm 0.2^{\mathrm{a}}$ & $73.77 \pm 4.46^{\text {efg }}$ & $7.69 \pm 2.01^{\text {bcde }}$ & $33.14 \pm 1.06^{\text {abcde }}$ & $40.83 \pm 2.53^{\text {bcde }}$ \\
\hline $2 f v$ & $106.3 \pm 4.9^{d}$ & $1.907 \pm 0.428^{\mathrm{de}}$ & $9.4 \pm 0.9^{a b}$ & $59.65 \pm 4.94^{\text {bcde }}$ & $13.98 \pm 2.20^{\text {efgh }}$ & $36.24 \pm 1.87$ bcdef & $50.22 \pm 3.82^{\text {fghij }}$ \\
\hline 3 & $136.3 \pm 0.6^{\mathrm{e}}$ & $2.469 \pm 0.454^{e f}$ & $4.8 \pm 1.2^{\mathrm{a}}$ & $104.35 \pm 5.21^{i j}$ & $0.30 \pm 0.39^{a}$ & $35.46 \pm 3.53^{\text {abcde }}$ & $35.76 \pm 3.34^{\mathrm{abc}}$ \\
\hline $3 v$ & $142.0 \pm 4.0^{\text {ef }}$ & $2.611 \pm 0.230^{\mathrm{fg}}$ & $5.8 \pm 0.3^{a}$ & $72.95 \pm 6.76^{\text {efg }}$ & $6.78 \pm 2.53^{\mathrm{abcd}}$ & $37.93 \pm 1.53^{\text {defg }}$ & $44.71 \pm 3.44$ defg \\
\hline $3 f$ & $145.0 \pm 3.6^{\text {efgh }}$ & $2.195 \pm 0.383^{\text {def }}$ & $3.1 \pm 0.1^{\mathrm{a}}$ & $78.87 \pm 3.82^{\mathrm{fgh}}$ & $5.82 \pm 2.10^{\mathrm{abcd}}$ & $32.19 \pm 2.91^{\text {bcdef }}$ & $38.01 \pm 1.12^{\mathrm{abcd}}$ \\
\hline $3 f v$ & $145.3 \pm 2.5^{\text {efgh }}$ & $1.747 \pm 0.300^{\mathrm{cd}}$ & $8.0 \pm 0.9^{a}$ & $66.65 \pm 7.41^{\text {cdef }}$ & $10.35 \pm 3.93^{\mathrm{de}}$ & $36.22 \pm 2.55^{\text {bcdefg }}$ & $46.58 \pm 4.22^{\text {efghi }}$ \\
\hline 4 & $69.8 \pm 1.5^{a}$ & $2.644 \pm 0.231^{\mathrm{fg}}$ & $4.5 \pm 1.0^{\mathrm{a}}$ & $72.82 \pm 14.72^{\text {efg }}$ & $7.40 \pm 6.10^{\text {bcde }}$ & $38.80 \pm 2.78^{\text {efgh }}$ & $46.20 \pm 6.85^{\text {efgh }}$ \\
\hline $4 v$ & $77.0 \pm 0.4^{\mathrm{ab}}$ & $2.302 \pm 0.259^{\text {def }}$ & $5.7 \pm 0.3^{a}$ & $69.57 \pm 2.28^{\text {cde }}$ & $8.08 \pm 1.74$ bcde & $38.32 \pm 2.57^{\text {efgh }}$ & $46.40 \pm 1.39^{\text {efghi }}$ \\
\hline $4 f$ & $78.3 \pm 1.1^{\text {bcd }}$ & $2.646 \pm 0.498^{\mathrm{fg}}$ & $3.4 \pm 0.2^{\mathrm{a}}$ & $69.55 \pm 8.15^{\text {cde }}$ & $10.54 \pm 4.61^{\text {def }}$ & $31.78 \pm 4.86^{\mathrm{fgh}}$ & $42.33 \pm 5.62^{\text {cde }}$ \\
\hline $4 \mathrm{fv}$ & $137.3 \pm 2.3^{\mathrm{e}}$ & $2.109 \pm 0.333^{\text {def }}$ & $3.9 \pm 1.1^{\mathrm{a}}$ & $61.46 \pm 0.73^{\text {bcde }}$ & $11.21 \pm 1.06^{\text {def }}$ & $41.04 \pm 2.75^{\mathrm{fgh}}$ & $52.25 \pm 1.81^{\text {ghij }}$ \\
\hline 5 & $139.7 \pm 5.0^{\mathrm{e}}$ & $0.465 \pm 0.065^{a}$ & $46.5 \pm 22^{\mathrm{e}}$ & $65.41 \pm 8.03^{\text {bcdef }}$ & $8.77 \pm 4.00^{\text {cde }}$ & $43.24 \pm 0.71^{\mathrm{gh}}$ & $52.02 \pm 3.50^{\text {fghij }}$ \\
\hline $5 \mathrm{v}$ & $141.0 \pm 4.6^{\mathrm{ef}}$ & $0.535 \pm 0.113^{a}$ & $62.7 \pm 4.0^{\mathrm{e}}$ & $68.02 \pm 5.58^{\text {cdef }}$ & $10.35 \pm 3.37$ de & $34.12 \pm 2.14^{\text {abcde }}$ & $44.48 \pm 2.20^{\text {def }}$ \\
\hline $5 f$ & $149.7 \pm 1.2^{\mathrm{fgh}}$ & $0.472 \pm 0.038^{a}$ & $42.3 \pm 2.0^{\mathrm{e}}$ & $85.90 \pm 3.44 \mathrm{gh}$ & $2.19 \pm 0.99^{a b c}$ & $37.64 \pm 2.44^{\text {cdefg }}$ & $39.82 \pm 2.39$ bcde \\
\hline $5 f v$ & $152.0 \pm 3.6^{\mathrm{gh}}$ & $0.425 \pm 0.047^{a}$ & $61.5 \pm 3.4^{\mathrm{e}}$ & $52.35 \pm 4.18^{b}$ & $19.51 \pm 2.91^{\mathrm{h}}$ & $33.75 \pm 1.79^{\text {abcde }}$ & $53.25 \pm 2.57^{\text {hij }}$ \\
\hline 6 & $142.7 \pm 2.9^{\text {efg }}$ & $0.788 \pm 0.193^{\mathrm{ab}}$ & $23.6 \pm 15^{c d}$ & $57.51 \pm 5.32^{\text {bcdebcd }}$ & $12.24 \pm 2.28^{\text {defg }}$ & $44.08 \pm 1.99^{h}$ & $56.33 \pm 3.87^{j}$ \\
\hline $6 \mathrm{v}$ & $146.0 \pm 5.6^{\text {efgh }}$ & $0.611 \pm 0.093^{\mathrm{ab}}$ & $36.1 \pm 1.9^{\text {def }}$ & $54.24 \pm 3.75^{b c}$ & $19.12 \pm 2.87^{\mathrm{h}}$ & $32.21 \pm 2.49^{\mathrm{abcd}}$ & $51.33 \pm 2.41^{\text {fghij }}$ \\
\hline $6 f$ & $150.0 \pm 4.2^{\mathrm{fgh}}$ & $0.582 \pm 0.123^{\mathrm{ab}}$ & $22.3 \pm 1.0^{\mathrm{bc}}$ & $89.95 \pm 3.55^{\mathrm{h}}$ & $1.55 \pm 0.84^{\mathrm{ab}}$ & $35.49 \pm 1.76$ abcdef & $37.04 \pm 1.69^{\mathrm{abcd}}$ \\
\hline $6 f v$ & $154.3 \pm 2.9^{\mathrm{h}}$ & $0.677 \pm 0.135^{\mathrm{ab}}$ & $37.9 \pm 3.4^{\text {de }}$ & $33.08 \pm 2.56^{a}$ & $30.56 \pm 2.43^{i}$ & $34.53 \pm 1.99$ abcde & $65.08 \pm 0.91^{k}$ \\
\hline
\end{tabular}

Values are means \pm SD

Means having the same letter for a parameter are not significantly different $(p<0.05)$ through the Tukey test

\section{RESULTS}

The schematic representation of the samples and samples photos are shown on Figure 1.

Table 1 shows the values of measured parameters: thickness of the layers, surface roughness, water contact angle and surface free energy and its total and polar component. ANOVA results indicate statistically significant differences for thickness, surface roughness, water contact angle and surface free energy and its total and polar component. The large $F$-value indicates there are more differences between groups than within groups. With a $p$-value $<0.0001$, the null hypothesis (there are no differences between different sample groups) is rejected. Post hoc analysis using Tukey's honestly significant difference (Tukey's HSD) was performed.

Printing or varnishing increases the thickness of the samples. It is related with the application of ink or varnish layer on the paper substrate. However, the thickness of the layers formed on the paper, differs for each paper, what is related with the various absorbency of the papers. The varnish layer is in the range of 1.3 to $9.9 \mu \mathrm{m}$ and the ink layer is in the range of 3.1 to $10 \mu \mathrm{m}$. In general the thickness of varnish layer is thinner than the ink layer.

The measured surface roughness of pure papers is much higher than overprinted or over varnished papers. It might be related with the proper cohesion forces in the ink or varnish layer. On the contrary, Gajadhur has observed the increase of surface roughness after printing or varnishing and at the same time, the varnish caused a much greater increase in the roughness surface than the ink coating (Gajadhur, 2018).

Gloss is a property of materials responsible for light reflection from a surface. The methods for gloss measurements depend on the kind of base. Firstly the gloss was measured with geometry $60^{\circ}$ for all samples, despite the uncoated papers prior and after finishing are matt. For this samples a measuring geometry with an angle of $85^{\circ}$ for uncoated paper samples was used, because the film coatings of the investigated inks and varnish for uncoated papers exhibit gloss below 10 units at a measuring geometry angle of $60^{\circ}$ according to ISO 2813 standard. However, the $60^{\circ}$ is most universal and might be used for all samples. The gloss of ink or varnish dried ink layer of overcoated glossy or coated papers are much higher that the gloss of uncoated papers. The gloss of the top layer is strongly influence by the substrate properties 
which may be related with a very thin layers. Furthermore, the influence of the gloss of the coatings is related with lower surface roughness of the coating.

Based on the obtained results of water contact angle and the values of components of the surface free energy (SFE), influence of printing and varnishing on SFE maybe assessed. The analyses of water contact angle and changes of water contact angle during time provides useful information about wetting of the solid by a liquid and its wettability. The values of water contact angles indicates that lowest wettability was determinate for papers prior printing or varnishing process. In general, the dried printing ink layer as a top layer exhibited higher values of water contact angles than varnished layer and simultaneously lower wettability. It might be related with the type of printing ink components. The values of water contact angles strongly affects the values of polar components of surface free energy. The values of polar components are very low and in the range of $0.26-12.24 \mathrm{~mJ} \cdot \mathrm{m}^{-2}$ for uncoated paper and coated paper, respectively. Simultaneously, the values of dispersive component are in the range of $31.38-44.08 \mathrm{~mJ} \cdot \mathrm{m}^{-2}$ for uncoated paper and coated paper, respectively. In general, the varnishing process increase the values of polar and dispersive component of surface free energy and, hence, the values of total surface free energy also increases. Furthermore, the values of total surface free energy of paper substrates are much lower than the values of dried varnish or ink layer.

\section{CONCLUSION}

The aim of this work was to analyze the surface properties of paper ink layer prior and after printing and varnishing process. The dried ink layer can be observed by human eye and the quality might be assessed by colorimetric method, whether the varnish is not observed by human eye or without reference samples. Based on our results, we can conclude, that the printing or varnishing increases the thickness of the sample. Next, the varnishing process increases the gloss of the samples (depending on the varnish used; in this work, semi-gloss water based dispersive varnished was used). Finally, the printing or varnishing finishing of the paper substrate affects the dispersive and polar part of surface free energy. Finishing of the paper substrate increases the total value of surface free energy. Simultaneously, we have observed poorer wettability of the coatings layers, so the varnish layer protects the print layer.

The surface free energy measurements as well as the measurement of the water contact angle might be a useful tool in order to observe whether the varnishing was used in order to improve the coating. However, this measurement needs a reference sample without varnished layer.

\section{REFERENCES}

[1] Car, I., Majnarić, I., Lozo, B.: "Colorimetric Changes Caused by UV Varnishing", Proceedings of 8th Conference On Information And Graphic Arts Technology, 37-40, 2018.

[2] Gajadhur, M.: "Paper and plastic roughness properties after surface refinement processes", Welding Technology Review 90 (3), 2018. doi:10.26628/wtr.v90i3.870.

[3] Galić, E., Ljevak, I., Zjakić, I.: "The Influence of UV Varnish on Colorimetric Properties of Spot Colors", Procedia Engineering 100, 1532-1538, 2015. doi:10.1016/j.proeng.2015.01.525.

[4] Holik, H., Moldenhauer, T., Rentrop, G.-H., Tschudin, P. F., von Kendenich, W. K.: "Introduction. In Handbook of Paper and Board", 1-31, 2013. doi:10.1002/9783527652495.ch1.

[5] Hudika, T., Tomašegović, T., Cigula, T., Poljičak, A.: "Analysis Of The Interactions In The "VarnishPhotopolymer" System", Proceedings of 8th International Symposium on Graphic Engineering and Design 2018, (Department of Graphic Engineering and design, Faculty of Technical Sciences, Novi Sad, 2018), pages 152-159, 2018. doi:10.24867/GRID-2018-p18.

[6] Majnarić, I., Mirković, I. B., Golubović, K.: "Influence of UV curing varnish coating on surface properties of paper", Tehnicki Vjesnik-Technical Gazette 19 (1), 51, 2012.

[7] Mirschel, G., Savchuk, O., Scherzer, T., Genest, B.: "Process control of printing processes with in-line NIR spectroscopy and elimination of the influence of the substrate on the prediction of the coating weight", Progress in Organic Coatings 76 (1), 86-93, 2013. doi:10.1016/j.porgcoat.2012.08.016. 


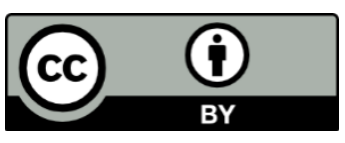

(C) 2020 Authors. Published by the University of Novi Sad, Faculty of Technical Sciences, Department of Graphic Engineering and Design. This article is an open access article distributed under the terms and conditions of the Creative Commons Attribution license 3.0 Serbia

(http://creativecommons.org/licenses/by/3.0/rs/). 